OPEN ACCESS

Edited by:

Gyohei Egawa,

Kyoto University, Japan

Reviewed by:

Sheng-Jie Yu,

Taichung Veterans General Hospital,

Taiwan

Sung-Wuk Jang,

University of Ulsan, South Korea

*Correspondence:

In Sik Kim

orientree@euljiac.kr

Eun Ju Yang

ejyang@dhu.ac.kr

${ }^{\dagger}$ These authors have contributed equally to this work

Specialty section:

This article was submitted to Inflammation,

a section of the journal

Frontiers in Immunology

Received: 26 December 2020 Accepted: 09 September 2021

Published: 08 October 2021

Citation:

Jeon $H$, Kim G, Kashif A, Hong MH, Lee J-S, Hong Y, Park BS, Yang EJ and Kim IS (2021) Pathogenic Mechanism of Der $p 38$ as a Novel Allergen Homologous to RipA and RipB Proteins in Atopic Dermatitis.

Front. Immunol. 12:646316. doi: 10.3389/fimmu.2021.646316

\section{Pathogenic Mechanism of Der p 38 as a Novel Allergen Homologous to RipA and RipB Proteins in Atopic Dermatitis}

\author{
Hyang Jeon ${ }^{1 \dagger}$, Geunyeong $\mathrm{Kim}^{1 \dagger}$, Ayesha Kashif ${ }^{1}$, Min Hwa Hong ${ }^{1}$, Ji-Sook Lee ${ }^{2}$, \\ Yujin Hong ${ }^{1}$, Beom Seok Park ${ }^{3}$, Eun Ju Yang ${ }^{4 *}$ and In Sik Kim ${ }^{1,5^{*}}$
}

\begin{abstract}
1 Department of Senior Healthcare, Graduate School, Eulji University, Uijeongbu, South Korea, ${ }^{2}$ Department of Clinical Laboratory Science, Wonkwang Health Science University, Iksan, South Korea, ${ }^{3}$ Department of Biomedical Laboratory Science, College of Health Science, Eulji University, Seongnam, South Korea, ${ }^{4}$ Department of Biomedical Laboratory Science, Daegu Haany University, Gyeongsan, South Korea, ${ }^{5}$ Department of Biomedical Laboratory Science, College of Health Science, Eulji University, Uijeongbu, South Korea
\end{abstract}

Atopic dermatitis (AD) is a chronic relapsing pruritic disease encompassing skin inflammation and barrier dysfunction. House dust mites are key allergens that augment the development of atopic dermatitis. We aimed to investigate the pathogenic mechanism of $A D$ due to Der p 38, recently identified by us. The frequency of IgE reactivity to Der $\mathrm{p} 38$ in $A D$ subjects was $52.6 \%(10 / 19)$ in the skin prick test and $57.9 \%(11 / 19)$ in the dot blot assay. In human keratinocyte HaCaT cells, Der p 38 triggered the impairment of filaggrin expression and induced pro-inflammatory cytokines such as IL-6, IL-8 and MCP-1 through TLR4, PI3K, AKT, C-Jun N-terminal kinase (JNK) and NF- $\mathrm{KB}$ pathway. Supernatants from Der $\mathrm{p}$ 38-treated cells blocked filaggrin expression and neutrophil apoptosis. The anti-apoptotic effect of the Der $\mathrm{p}$ 38-released molecules on neutrophils was accomplished by inhibition of the caspase 9/3 pathway, and by increased MCL-1 expression and BCL-2/BAX expression ratio. In C57BL/6 wild type (WT) mice, Der p 38 induced a dose-dependent increase of AD-like skin lesions, with enhanced expressions of total and Der p 38-specific IgE. Der p 38 also diminished the expressions of skin barrier proteins and induced JNK activation. However, the AD-like features following cutaneous Der p 38 exposure were observed to be reduced in the TLR4 knockout (KO) group, as compared to the WT group. Skin infiltration of neutrophils, eosinophils and mast cells was increased in the WT mice, but was not portrayed in the TLR4 KO mice. These findings indicate that Der p 38 is a novel mite allergen that triggers AD by lowering skin barrier proteins and increasing inflammatory cells. Results of this study have thereby paved the way to unveil the pathogenic mechanisms of $A D$.

Keywords: Der p 38, atopic dermatitis, filaggrin, TLR4, skin barrier 


\section{INTRODUCTION}

Atopic dermatitis (AD) is a pruritic, relapsing and chronic inflammatory skin condition with variable clinical features (1). $\mathrm{AD}$ pathogenesis has mainly been explained by two pathogenic mechanisms: the "inside-to-outside" and "outside-to-inside" hypothesis $(2,3)$. In the inside-to-outside hypothesis, traditionally immunological aberrations are related to a Th2 immunity leading to increased IL-4, IL-5, IL-13 and IgE in an acute phase, subsequently progressing to chronic inflammation, thereby ascertaining the transition of Th2 to Th1 immunity. Another hypothesis assumes the importance of an intrinsic defect in the epidermal barrier. AD pathogenesis research has recently targeted that immune and skin barrier abnormalities contribute to the overall phenotype (4). Filaggrin disruption allows exogenous immune stimuli such as allergens to enter the skin and activate immune responses including cytokine secretion, which subsequently suppresses filaggrin expression, and vice versa (5-7). Moreover, this vicious cycle of filaggrin regulation is related to activation of $\mathrm{c}$-Jun $\mathrm{N}$-terminal kinase (JNK) and NF-KB $(8,9)$.

House dust mite (HDM) allergens play essential roles in the onset and development of $\mathrm{AD}(10-13)$. The major mite allergenic components, viz., protease allergens (group 1,3) and nonprotease allergens (group 2, 7), are derived from Dermatophagoides pteronyssinus (DP) or Dermatophagoides farinae (DF), and induce serum-specific IgE and Th2 immunity. TLR4 is a major receptor in HDM-induced allergic inflammation (14-17). TLR4 acts as a critical factor in severity of $\mathrm{AD}$ in the presence of its ligand LPS-induced infections, and this alteration of TLR4 expression is consequential in the skin of $\mathrm{AD}(18,19)$. However, studies have reported that TLR4 is a negative regulator in the pathogenic mechanism of $\mathrm{AD}$. Deletion of TLR4 suppresses AD-like symptoms and skin inflammation in $\mathrm{AD}$-like mice due to fungus allergens and 2,4-dinitrochlorobenzene (DNCB) (20-22). Der p 2 does not induce AD via TLR4, but through TLR2 (23). Thus, relationship of the allergen and TLR4 with AD has remained controversial so far.

Based on the substantial available evidence that cutaneous defect of the skin barrier, allergen sensitization and TLR4 are important factors in $\mathrm{AD}$ pathogenesis, we examined, for the first time, the skin barrier dysfunction and TLR4-involved inflammation due to a novel allergen, Der $\mathrm{p}$ 38. This novel allergen was discovered by us from the DP extract, and is registered in the allergen database approved by the WHO/IUIS Allergen Nomenclature Sub-committee.

\section{MATERIALS AND METHODS}

\section{Reagents}

DP was obtained from the Korea National Arthropods of Medical Importance Resource Bank (Yonsei University, Seoul, Korea) and Cosmo Bio (Tokyo, Japan). CLI-095, an inhibitor of Toll like receptor 4 (TLR4i), was purchased from Invitrogen (San Diego, CA, USA). PI3K inhibitor (LY294002), AKT inhibitor (AKTi), JNK inhibitor (SP600125) and NF-KB inhibitor (BAY-
11-7085) were purchased from Calbiochem (San Diego, CA, USA). Antibodies against phosho-ERK1/2, MCL-1, BCL-2 and BAX were purchased from Cell Signaling Technology (Beverly, MA, USA). Antibodies against filaggrin, involucrin, loricrin, phospho-AKT, AKT, phospho-JNK, JNK, ERK2, caspase 3, and caspase 9 were obtained from Santa Cruz Biotechnology (Santa Cruz, CA, USA). Antibodies against Ly6G and tryptase were obtained from Abcam (Cambridge, UK). Antibodies against eosinophil peroxidase were obtained from Bioss Antibodies (Woburn, MA, USA) (Supplementary Material).

\section{Sequence Alignment}

The protein sequences of RipB [Protein Data Bank (PDB) Code: 3PBI], RipA [PDB code: 3PBC] and Der p38 (GenBank Protein ID: QLY71953) proceeded multiple sequence alignment using Clustal Omega program (https://www.ebi.ac.uk/Tools/msa/ clustalo). The aligned sequences were represented by the ESPript 3.0 program to render sequence similarities and secondary structure information (http://espript.ibcp.fr/ESPript/ ESPript/index.php).

\section{Expression of Recombinant Der p 38 and Generation of the Antibody}

cDNAs of DP were synthesized from total RNAs of DP using the iScript cDNA synthesis kit (Bio-Rad, Hercules, CA, USA). Der $p$ 38 cDNA (GenBank accession number MT273069.1) was synthesized by PCR using forward (5'- ACT CAG GAT CCG ATG CAA GTT TAT GGT AAT GGT-3') and reverse primers (5'- ACT ACG CGG CCG CTC ACC AAC ATC GTG CAA CAT TAG $\left.C-3^{\prime}\right)$, and the amplified cDNA was inserted into the plasmid pETDuet-1(Merck Millipore, Darmstadt, Germany). E. coli Orgami B (DE3) cells transformed with the pETDuet-1 expression vector were grown to an A600 $\mathrm{nm}$ of 0.6 before induction with $0.5 \mathrm{mM}$ isopropyl $\beta$-D-1-thiogalactopyranoside (IPTG). Subsequently, the harvested cells were lysed by sonication in lysis buffer followed by purification using a nickel column (Merck Millipore). A $10 \mathrm{kDa}$ Amicon Ultra concentrator (Millipore) was used for concentrating the protein, followed by purification using a Superdex 200 column attached to an ÄKTA FPLC system (GE Healthcare). The endotoxin level was determined by the Toxin sensor chromogenic LAL endotoxin assay kit (GenScript, Piscataway, NJ, USA). The mandatory removal of endotoxins was achieved by using the ToxinEraser endotoxin removal kit (GenScript). Sodium dodecyl sulfide -polyacrylamide gel electrophoresis (SDS-PAGE) was performed for identification of the protein, which was stained with Coomassie brilliant blue. Protease activity of Der p 38 was measured using the fluorescent protease assay kit (Pierce, Rockford, IL, USA). The purified protein was aliquoted and stored at $-70^{\circ} \mathrm{C}$ for further use. Polyclonal antibodies against Der p 38 were produced by immunizing rabbits. After first injection of the purified Der p 38, rabbits were boosted by the same protein two times. Enzyme-linked immunosorbent assay (ELISA) was performed as activity test of the antibodies after coating with Der p 38 protein. Antibodies at diluted sera (1:1000, 1:5000, 1:10000, and 1:50000) showed O.D. greater than (>) 1.0. 


\section{Subjects}

Healthy subjects and $\mathrm{AD}$ volunteers with no medication were recruited at the Eulji University for blood donation and undergoing skin prick test (Table 1 and Supplementary Table 1). The human blood protocol and associated consent forms were reviewed and approved by the Institutional Review Board (IRB) of the Eulji University. Conventional skin prick test was conducted according to the instructions of the SoluprickR test. Histamine (positive control), DP, DF (ALK Horsholm, Denmark), Der p 1, Der p 2 (INDOOR Biotechnologies, Charlottesville, VA, USA) and Der p 38 were used as test materials. Recombinant allergen proteins $(10 \mu \mathrm{g} / \mathrm{mL})$ were solubilized in phosphate buffered saline (PBS, $\mathrm{pH}$ 7.4) before using in this test. A positive result was determined as a $\geq 1+$ (i.e., a wheal $\geq 3 \mathrm{~mm}$ diameter).

\section{IgE Reactivity to Der $\mathbf{p} 38$}

IgE reactivity was determined by the dot assay. Briefly, recombinant Der p 38 proteins were added to nitrocellulose membrane and dried. The membrane was blocked with 3\% bovine serum albumin (BSA) solution for $30 \mathrm{~min}$, and then incubated with diluted (1:10) sera of healthy or AD subjects for $1 \mathrm{~h}$. After incubating with secondary mouse anti-human $\operatorname{IgE}$ antibody (Abcam, Cambridge, UK), the membrane was developed using the enhanced chemiluminescence detection system (Thermo Scientific, Waltham, MA, USA).

To measure the concentration of IgE against Der $\mathrm{p} 38$ protein in the sera of mice, plates were coated with Der $\mathrm{p} 38$ protein at a concentration of $1 \mu \mathrm{g} / \mathrm{mL}$ per well, in carbonate buffered solution at $4^{\circ} \mathrm{C}$ overnight. For preventing non-specific reaction, 5\% BSA solution was added to each well. After washing three times, the plate was incubated with sera (1:5), followed by incubation with biotin-labeled goat anti-mouse IgE and SAv-HRP reagent added to each well. For stopping the reaction, $2 \mathrm{M} \mathrm{H}_{2} \mathrm{SO}_{4}$ solution was added to each well, and absorbance was measured at $450 \mathrm{~nm}$ using an automated microplate reader (Molecular Devices, Chicago, IL, USA).

\section{Total IgE and Cytokine ELISA}

The human IgE kit (Carlsbad, CA, USA) and mouse IgE ELISA set (BD Biosciences, San Diego, CA, USA) were used to evaluate the total IgE in the sera of human and mice, respectively, according to the recommended protocols. To measure cytokine concentration, HaCaT cells were stimulated with Der p 38 in a time-dependent manner, and supernatants were collected. OptEIA Set human IL-6, IL-8 and MCP-1 (BD Biosciences), were used for estimating concentrations of IL-6, IL-8 and MCP-1, respectively, in the supernatants, according to the manufacturer's guidelines. Absorbance was measured at 450-550 nm using the automated microplate reader procured from Molecular Devices (San Jose, CA, USA).

\section{Cell Culture}

The human keratinocyte cell line (HaCaT) was maintained in Dulbecco's modified Eagle's medium supplemented with $10 \%$ FBS and penicillin/streptomycin, under an atmosphere of $95 \%$ air $/ 5 \% \mathrm{CO}_{2}$ at $37^{\circ} \mathrm{C}$.

\section{Western Blotting and NF-kB p65 Transcription Factor Assay}

$\mathrm{HaCaT}$ cells were treated with $10 \mu \mathrm{g} / \mathrm{mL}$ Der p 38 for the indicated time, and then harvested cells were lysed in lysis buffer (TransLab, Daejeon, Korea). The homogenate was centrifugated at $12,000 \mathrm{xg}$ for $15 \mathrm{~min}$ at $4^{\circ} \mathrm{C}$, and the supernatant was collected as total lysate. Protein concentration of the lysate was measured by a protein assay kit (Thermo Scientific). Following separation of the protein samples $(50 \mu \mathrm{g} / \mathrm{lane})$ by $10 \%$ SDS-PAGE, the transferred nitrocellulose membrane was sequentially incubated with primary $(1: 1,000)$ and secondary antibody $(1: 3,000)$ for $1 \mathrm{~h}$ at room temperature, and developed using the Enhanced Chemiluminescence Western blotting

TABLE 1 | Demographic and clinical characteristics of normal and AD subjects.

\begin{tabular}{|c|c|c|c|c|}
\hline & \multicolumn{2}{|c|}{ Normal $(n=19)$} & \multicolumn{2}{|c|}{$A D(n=19)$} \\
\hline Number of subjects (female/male) & \multicolumn{2}{|c|}{$19(15 / 4)$} & \multicolumn{2}{|c|}{$19(15 / 4) A D(12), A D+A R(5), A D+A S(2)$} \\
\hline Age (years) & \multicolumn{2}{|c|}{$24.9 \pm 5.2(20 \sim 41)$} & \multicolumn{2}{|c|}{$23.5 \pm 6.0(20 \sim 48)$} \\
\hline Total lgE (ng/mL) & \multicolumn{2}{|c|}{$158.6 \pm 171.7(38.9 \sim 603.9)$} & \multicolumn{2}{|c|}{$361.3 \pm 457.9(47.8 \sim 1594.5)^{\star}$} \\
\hline $\mathrm{DP}+, \mathrm{DF}+$ & \multicolumn{2}{|c|}{$5(26.3 \%)$} & \multicolumn{2}{|c|}{$17(89.5 \%)$} \\
\hline $\mathrm{DP}+, \mathrm{DF}-$ & \multicolumn{2}{|c|}{$1(5.3 \%)$} & \multicolumn{2}{|c|}{$2(10.5 \%)$} \\
\hline DP-, DF+ & \multicolumn{2}{|c|}{$0(0 \%)$} & \multicolumn{2}{|c|}{$0(0.0 \%)$} \\
\hline DP-, DF- & \multicolumn{2}{|c|}{$13(68.4 \%)$} & \multicolumn{2}{|c|}{$0(0.0 \%)$} \\
\hline Der $\mathrm{p} 1$ & \multicolumn{2}{|c|}{$2(10.5 \%)$} & \multicolumn{2}{|c|}{$14(73.7 \%)$} \\
\hline Der $\mathrm{p} 2$ & \multicolumn{2}{|c|}{$3(15.8 \%)$} & \multicolumn{2}{|c|}{$12(63.2 \%)$} \\
\hline \multirow[t]{2}{*}{ Der p 38} & \multicolumn{2}{|c|}{$3(15.8 \%)$} & \multicolumn{2}{|c|}{$10(52.6 \%)$} \\
\hline & $\mathrm{HDM}+(\mathrm{n}=6)$ & $\mathrm{HDM}-(\mathrm{n}=13)$ & $\mathrm{HDM}+(\mathrm{n}=19)$ & $\mathrm{HDM}-(\mathrm{n}=0)$ \\
\hline Der $\mathrm{p} 1$ & $2(33.3 \%)$ & $0(0.0 \%)$ & $14(73.7 \%)$ & $0(0.0 \%)$ \\
\hline Der $\mathrm{p} 2$ & $3(50.0 \%)$ & $0(0.0 \%)$ & $12(66.2 \%)$ & $0(0.0 \%)$ \\
\hline Der p 38 & $3(50.0 \%)$ & $0(0.0 \%)$ & $10(52.6 \%)$ & $0(0.0 \%)$ \\
\hline
\end{tabular}

$A D$, atopic dermatitis; $A R$, atopic rhinitis; $A S$, asthma.

*Significant difference $(p<0.05)$ between normal and $A D$ subjects.

A positive result in the skin prick test is determined as a $\geq 1+$ (i.e., a wheal $\geq 3 \mathrm{~mm}$ diameter).

$H D M+$ is described as at least one of DP and DF is + in the skin prick test. 
Detection System (Amersham Pharmacia Biotech, Piscataway, NJ, USA). The same blot was stripped and re-probed with internal control antibodies, such as anti-ERK2 antibodies. For evaluating $\mathrm{NF}-\kappa \mathrm{B}$ activity, nuclear lysates were assessed for NF-kB DNAbinding activity using NF- $\kappa \mathrm{B}$ p 65 transcription factor assay kit (Abcam, Cambridge, UK) as described in our previous paper (24).

\section{Separation of Neutrophils and Eosinophils}

Heparinized peripheral blood was collected from healthy and AD subjects, and layered on Ficoll-Hypaque gradient solution. After centrifugation, the leukocytes were collected, and the erythrocyte contaminants were eliminated by RBC lysis buffer. Both neutrophils (CD16+) and eosinophils (CD16-) were separated by applying the CD16 microbeads magnetic cell sorting kit (Miltenyi Biotec, Bergisch Gladbach, Germany). Isolated cells were washed three times by PBS buffer and resuspended in RPMI 1640 medium containing 10\% fetal bovine serum (FBS) and antibiotics. Purity of the cells was determined to be greater than $97 \%$, as evaluated by cell counting after subjecting to WrightGiemsa stain.

\section{Detection of Apoptosis}

Neutrophils and eosinophils were incubated with FITC-labeled annexin V and propidium iodide (PI) (BD Biosciences, San Diego, CA, USA) for $15 \mathrm{~min}$ at room temperature. The stained cells were analyzed by RF-500 (Sysmex Corporation, Kobe, Japan) and were divided into early apoptotic cells (Annexin V+, PI-), late apoptotic cells or necrotic cells (Annexin V +, PI +) and viable cells (Annexin V-, PI-). Early and late apoptotic cells are considered apoptotic cells. The percentage of cells showing annexin V+/PI- and annexin V+l $\mathrm{PI}+$ cells were considered as apoptotic neutrophils and eosinophils.

\section{AD Induction Subsequent to Der p 38 Administration}

C57BL/10ScNJ and C57BL/10ScNJ TLR4 knockout (KO) mice were kindly provided by Jeong Won-Il (Korea Advanced Institute of Science and Technology; KAIST). All animals were maintained in a specific pathogen-free (SPF) facility. All the animal experiments were performed in accordance with the protocols approved by the Institutional Animal Care and User Committee of Eulji University. WT mice were randomly divided into five groups ( $\mathrm{n}=5)$ : control (Con), DP (100 $\mu$ g per dose), and Der p 38 treatment $(20,50$, and $100 \mu$ g per dose) groups. TLR4 KO mice were classified into three groups: control (Con) and Der p 38 treatment (20 and $50 \mu \mathrm{g}$ per dose) groups. The mice were allowed to adapt for 1 week before experimental procedures. A day before the first allergen exposure, the mice backs were shaved with an electric razor. The stimulators suspended in PBS or PBS (control), were applied to a $2 \times 2 \mathrm{~cm}$ patch of sterile gauze. The patch was secured by wrapping the mice with a band aid. After 6 days, the patch was removed, and $24 \mathrm{~h}$ later a new patch was applied. This continued for a total of five patches over the 5 weeks period. The clinical skin severity score was evaluated using the modified scoring atopic dermatitis (SCORAD) index. A score of $0-3$ ( 0 , none; 1 , mild; 2 , moderate; 3 , severe) was assigned for each of the following five symptoms: pruritus/itching, erythema/ hemorrhage, scarring/dryness, excoriation/erosion, and edema.

\section{Histological Analysis}

Subsequent to sacrifice of the mice by $\mathrm{CO}_{2}$ asphyxiation, the dorsal skin was removed, fixed in Carnoy's solution (SigmaAldrich Korea, Seoul, Korea), embedded in paraffin and sectioned ( $3 \mu \mathrm{m}$ thick slices) using a microtome (Leica, Nussloch, Germany). The sections were stained with hematoxylin-eosin solution (Sigma-Aldrich Korea). Thickness of the epidermis and dermis were evaluated as described in a previous paper (23). For immunohistochemical staining for filaggrin, loricrin, involucrin and Ly6G, eosinophil peroxidase, and tryptase, sections were deparaffinized by xylene. A solution of proteinase $\mathrm{K}$ was applied for $30 \mathrm{~min}$ for antigen retrieval, followed by treatment with $0.3 \% \mathrm{H}_{2} \mathrm{O}_{2}$ in methanol for $40 \mathrm{~min}$. Slides were blocked by blocking buffer for $1.5 \mathrm{~h}$, and subsequently incubated for $90 \mathrm{~min}$ (filaggrin) or overnight (loricrin, involucrin, Ly6G, eosinophil peroxidase, and tryptase) at $4^{\circ} \mathrm{C}$ with the indicated primary antibodies. After washing, the slides were incubated with secondary antibodies for $60 \mathrm{~min}$ (loricrin and involucrin) or $80 \mathrm{~min}$ (filaggrin) at room temperature. After incubating with $\mathrm{AB}$ and 3,3'-diaminobenzidine (DAB reagents), the specimens were counterstained with hematoxylin and examined under light microscopy (Leica Microsystems, Wetzlar, Germany) for histological evaluation. Vectastain elite ABC HRP kit (Vector Labs, Burlingame, CA, USA) and DAB chromogen were used for detecting antibodies.

\section{Statistical Analysis}

Data are presented as the means \pm SD. Statistical intergroup differences were analyzed using a paired t-test for a two-group comparison and one-way ANOVA for more than two groups. The SPSS statistical software package (Chicago, IL, USA) was used for statistical evaluation. A $p$ value $<0.05$ is considered statistically significant.

\section{RESULTS}

\section{Der p 38 Has IgE Reactivity in AD Subjects}

Der $\mathrm{p} 38$ was purified as a TLR4-binding protein from DP extract using a column attached with recombinant TLR4 protein, as compared to finding novel allergens with an IgE-binding frequency $(25,26)$. The protein sequence of Der p 38 is homologous to that of RipA and RipB proteins, and alignment of Der p 38 with these proteins is presented in Figure 1A. A recombinant Der $\mathrm{p} 38$ protein was produced as described in the Materials and Methods section (Figure 1B). The interaction of recombinant Der p 38 with TLR4 was confirmed using a TLR4bound column (Supplementary Figure 1). Content of Der p 38 in DP extract was approximately evaluated by comparing with the concentration of recombinant Der p 38 (Figure 1C). Since RipA and RipB proteins are peptidoglycan endopeptidases, we examined the proteolytic activity of Der $\mathrm{p}$ 38. As shown in Figure 1D, Der p 38 showed weak activity, which was lower than 

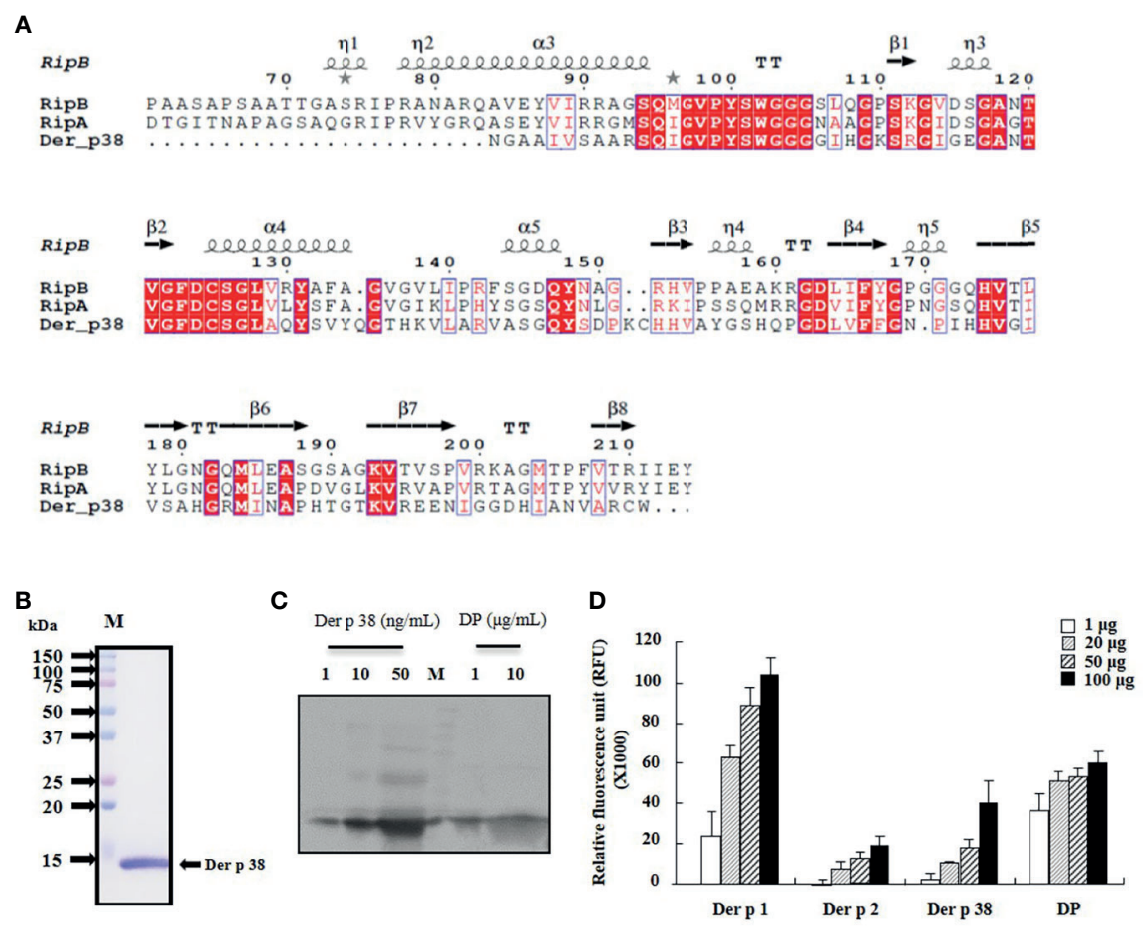

E

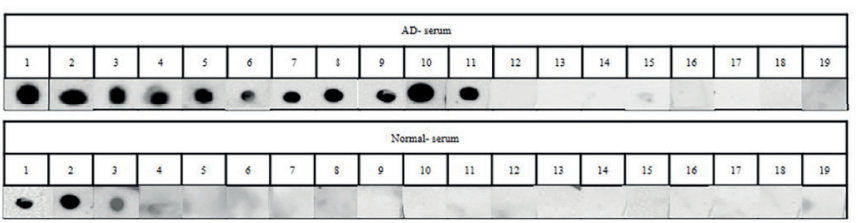

FIGURE 1 | Der p 38 shows lgE reactivity in AD subjects. (A) Der p 38 amino acid sequence is aligned with the RipA and RipB proteins. Red box (strict identity). Blue frame (similarity across groups). Red character (similarity in a group). (B) Der p 38 cDNA were amplified by PCR using gene specific primer. The cDNA was cloned to the vector and transformed into $E$ coli. Recombinant Der p 38 protein was produced, separated by SDS-PAGE, and stained with Coomassie brilliant blue. (C) Natural Der $p 38$ protein in DP extract was detected by Western blotting using antibodies against Der $p$ 38. (D) Protease activity of Der $p 38$ was measured by a protease activity kit. (E) Dot blot assay was performed with sera of healthy and AD subjects.

activity of Der $\mathrm{p} 1$. Skin prick test was performed to investigate the exposure of Der p 38 in $\mathrm{AD}$ subjects and 52\% patients were found to be sensitized by Der p 38 (Table 1). Positive reactions to Der p 1 and Der p 2 were $73.7 \%$ and $63.2 \%$ of the AD groups, respectively. In addition, Der p 38+ results were determined to be $57.9 \%$, using the dot blot assay (Figure 1E).

\section{Der p 38 Diminishes Filaggrin Expression via TLR4, PI3K, AKT, JNK and NF- $\mathrm{KB}$ in Human Keratinocyte HaCaT Cells}

Since skin barrier proteins are critical elements in maintaining the skin structure and their dysfunction is related to $\mathrm{AD}$ aggravation, we examined whether Der p 38 affects the expression of the relevant proteins in HaCaT cells. As shown in Figure 2A, exposure to Der p 38 inhibits filaggrin expression and weakly downregulates the expressions of loricrin and involucrin (Figure 2A). Since JNK and NF- $\mathrm{BB}$ are important proteins in filaggrin expression $(8,9)$, we investigated the association of both proteins with the filaggrin downregulation mechanism after Der p 38 treatment. Inhibitors of TLR4, JNK and NF- $\kappa \mathrm{B}$ reversed the inhibition of filaggrin expression exerted by Der $\mathrm{p} 38$, and increased JNK activation, in a time-dependent manner (Figures 2B, C). To find the upstream molecules of JNK, we used specific signal inhibitors. TLR4i, LY294002 and AKTi suppressed the JNK phosphorylation and blocked the filaggrin expression inhibited by Der p 38 (Figures 2D, E). Furthermore, AKT activation was confirmed after treatment with Der p 38 (Figure 2F). NF- $\mathrm{\kappa B}$ activity was time-dependently increased by Der $\mathrm{p} 38$, which was suppressed by inhibitors of TLR4, PI3K, AKT and JNK (Figures 2G, H). Since alteration of TLR4 expression is important in regulating the agonistic effect of TLR4 (27), we investigated whether Der p 38 increases both total and surface expressions of TLR4. We observed that the total and surface TLR4 expressions remained unaltered after Der p 38 stimulation (Supplementary Figure 2). 


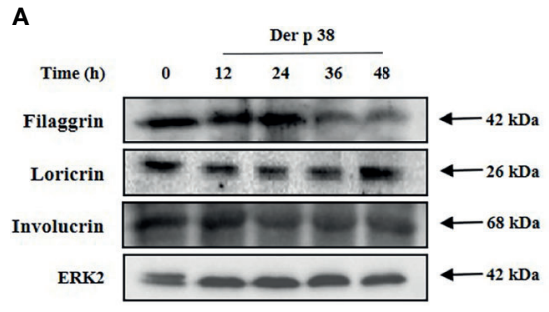

C

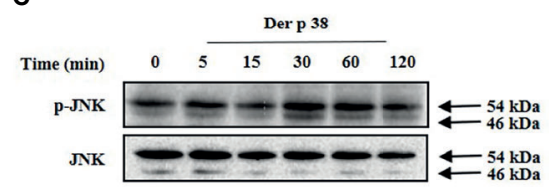

E

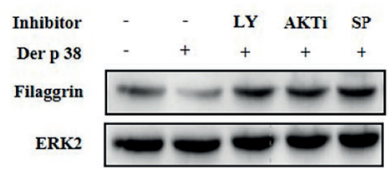

G

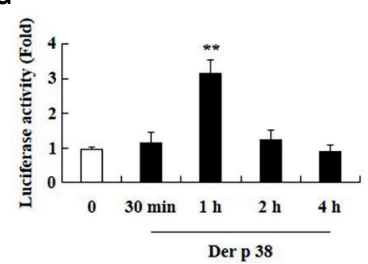

B

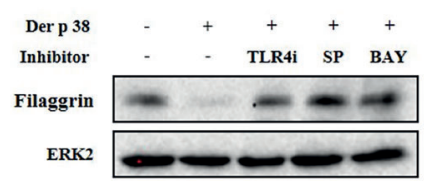

D

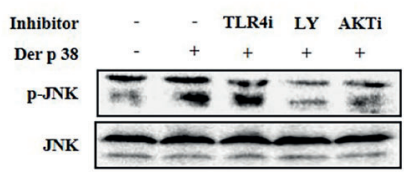

$\mathbf{F}$

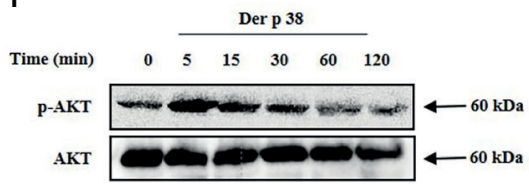

H

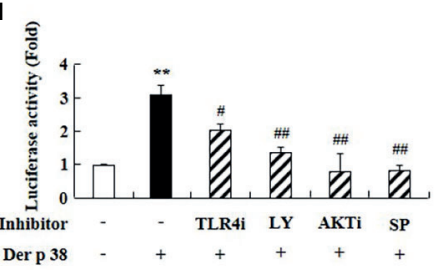

FIGURE 2 | Der $\mathrm{p} 38$ diminishes filaggrin expression via TLR4, PI3K, AKT, JNK and NF-kB in human keratinocyte HaCaT cells. (A, C, F) HaCaT cells were treated with 10 $\mu \mathrm{g} / \mathrm{mL}$ Der $\mathrm{p} 38$ for the indicated duration. The harvested cells were lysed, and filaggrin, loricrin, involucrin (A), phospho-JNK (C), and phospho-AKT (F) were analyzed by Western blotting. (B, D) The cells were pretreated with $2 \mu \mathrm{M}$ TLR4i, $10 \mu \mathrm{M}$ LY294002 (LY), $10 \mu \mathrm{M}$ AKTi, $10 \mu \mathrm{M}$ SP600125 (SP) or $10 \mu \mathrm{M}$ BAY-11-7085 (BAY) for $1 \mathrm{~h}$, following Der p 38 treatment for $48 \mathrm{~h}$ (B) or $30 \mathrm{~min}$ (D). Filaggrin and phospho-JNK were analyzed by Western blotting. (E) The cells were pretreated with $10 \mu \mathrm{M} \mathrm{LY} 294002$, $10 \mu \mathrm{M}$ AKTi or $10 \mu \mathrm{M}$ SP600125, after which they were treated with Der $\mathrm{p} 38$ for $48 \mathrm{~h}$. Filaggrin was analyzed by Western blotting. ERK2 was used as an internal control. (G, H) The cells were treated with $10 \mu \mathrm{g} / \mathrm{mL}$ Der p 38 in a time dependent manner (G), or $10 \mu \mathrm{g} / \mathrm{mL}$ Der p 38 after pretreatment with $2 \mu \mathrm{M}$ TLR4i, $10 \mu \mathrm{M} \mathrm{LY} 294002,10 \mu \mathrm{M}$ AKTi, or $10 \mu \mathrm{M}$ SP600125 (H). After lysis of the harvested cells, NF-KB activity in the lysates was evaluated by the luciferase assay. The data are presented relative to the control, which was set at 1 as the mean $\pm S . D(n=3) .{ }^{* *} p<0.01$ indicates a significant difference between untreated and Der $p 38$-treated groups, and ${ }^{\#} p<0.05$ and ${ }^{\# \#} p<$ 0.01 indicate significant difference between the Der $\mathrm{p} 38$-treated group and the inhibitor-treated groups.

\section{Der p 38 Increases Mediator Secretion in Human Keratinocyte HaCaT Cells, Which Prevents Filaggrin Expression and Neutrophil Apoptosis}

We next investigated the relationship of the decreased filaggrin expression by Der p 38, with cytokine secretion. Filaggrin expression was suppressed by supernatant of cells treated with Der p 38 (Figure 3A). Since Der p 38 in the supernatant after treatment affects filaggrin expression, we evaluated the effect of media incubated with Der $\mathrm{p} 38$ for $48 \mathrm{~h}$; this media had no effect on filaggrin expression. To clarify the effect of the supernatant, we evaluated for levels of cytokines, such as IL-6, IL-8, and MCP-1. Exposure to Der p 38 increased these cytokine levels in a timedependent manner (Figure 3B). Upregulation of IL-6, IL-8 and MCP-1 was suppressed by inhibitors of TLR4, PI3K, AKT, JNK and $\mathrm{NF}-\kappa \mathrm{B}$ (Figure 3C). Since these cytokines may be involved in survival of inflammatory cells, as reported in our previous papers $(15,27)$, we investigated alteration of granulocyte apoptosis due to Der $\mathrm{p}$ 38. Compared to the control supernatants, neutrophil apoptosis was inhibited by the supernatant treated with Der p 38, but eosinophil apoptosis was not altered (Figure 3D). The activation of caspase 9 and caspase 3 was involved in the inhibitory mechanism exerted by Der $\mathrm{p}$ 38-treated supernatant (Figure 3E). Additionally, Der p 38 increased both MCL-1 expression and the ratio of BCL-2/BAX expression, indicating that these mechanisms delay neutrophil apoptosis (Figure 3F).

\section{Der p 38 Induces AD-Like Phenotypes, Including Filaggrin Downregulation, via TLR4 in Mice}

For evaluating the effect of Der p 38 in the pathogenesis of $\mathrm{AD}$, we examined both histological and serological alterations in 

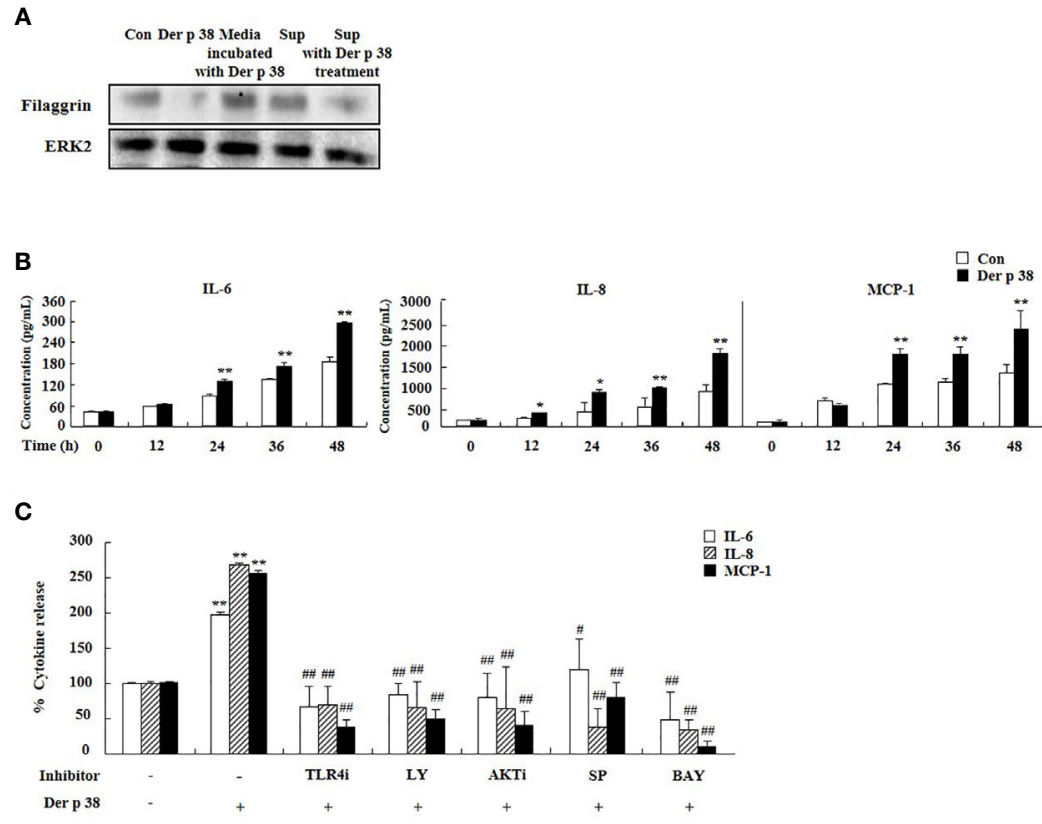

D

E
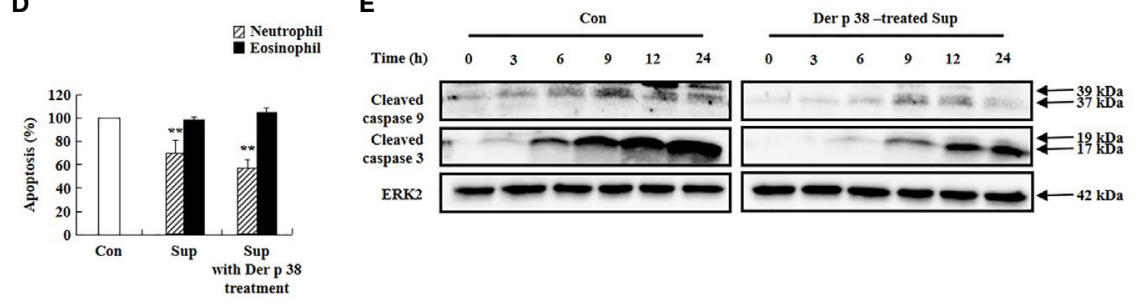

$\mathbf{F}$

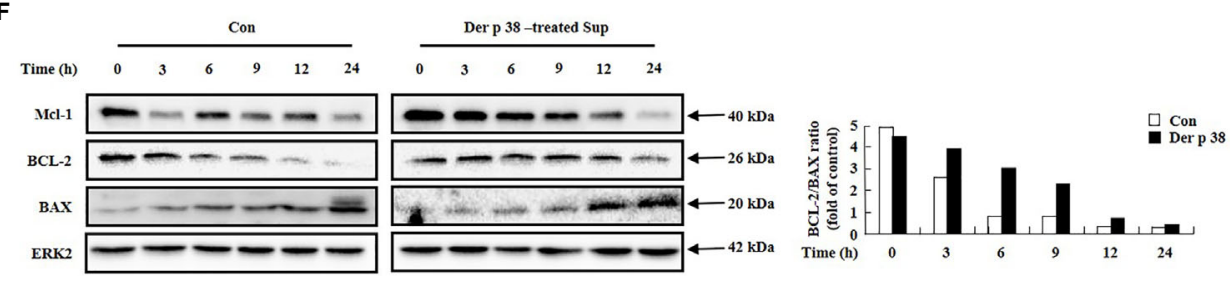

FIGURE 3 | Der p 38 increases cytokine secretion in human keratinocyte HaCaT cells, thereby preventing filaggrin expression and neutrophil apoptosis. (A) HaCaT cells were treated with $10 \mu \mathrm{g} / \mathrm{mL}$ Der p 38 for $48 \mathrm{~h}$. Supernatant (Sup) was collected, and the other cells were treated with the supernatant for $48 \mathrm{~h}$. The harvested cells were lysed in lysis buffer and the homogenate was centrifugated, and the supernatant was collected as total lysate. Following separation of the protein samples by $10 \%$ SDS-PAGE, the transferred nitrocellulose membrane was sequentially incubated with anti-filaggrin $(1: 1,000)$ and secondary antibody $(1: 3,000)$ for $1 \mathrm{~h}$ at room temperature, and developed using the Enhanced Chemiluminescence Western blotting Detection System. ERK2 expression is used as an internal control. (B, C) Cells were treated with $10 \mu \mathrm{g} / \mathrm{mL}$ Der p 38 for the indicated time (B), or for $48 \mathrm{~h}$ after pretreatment with $2 \mu \mathrm{M}$ TLR4i, $10 \mu \mathrm{M}$ LY294002 (LY), $10 \mu \mathrm{M}$ AKTi, $10 \mu \mathrm{M}$ SP600125, and $10 \mu \mathrm{M}$ BAY-11-7085 (BAY) (C). The supernatant was collected and analyzed by ELISA. (D) Neutrophils and eosinophils were treated with the supernatant after treatment with $10 \mu \mathrm{g} / \mathrm{mL}$ Der $\mathrm{p} 38$. Apoptosis was analyzed by measuring the binding of annexin V-FITC and PI. The data are presented relative to the control, which was set at $100 \%$ as the mean \pm S.D $(n=3) .{ }^{*} p<0.05$ and ${ }^{* *} p<0.01$ indicate a significant difference between the untreated and Der $p$ 38-treated groups, and $\# p<0.05$ and ${ }^{\# \#} p<0.01$ indicate significant difference between the Der $p 38$-treated group and the inhibitor-treated groups. (E, F) Activation and expression of the indicated signal proteins were evaluated by Western blotting. Lower panel (F) is the ratio of BCL2/BAX using densitometry.

mice. In WT mice, the skin became thick, and severe erythema, hemorrhage, edema, scarring and erosion were observed after Der p 38 administration; this skin severity was decreased in TLR4 KO mice (Figure 4A). Histological features showed severe skin lesions and inflammation, and increased thickness of epidermis and dermis due to Der p 38 (Figures 4B-D). Absence of TLR4 decreased these effects of Der p 38. Moreover, total IgE and Der p 38-specific IgE in WT mice was higher than in TLR4 KO mice (Figures 4E, F). To investigate alterations of skin barrier proteins and inflammatory cells in detail, we applied 
A
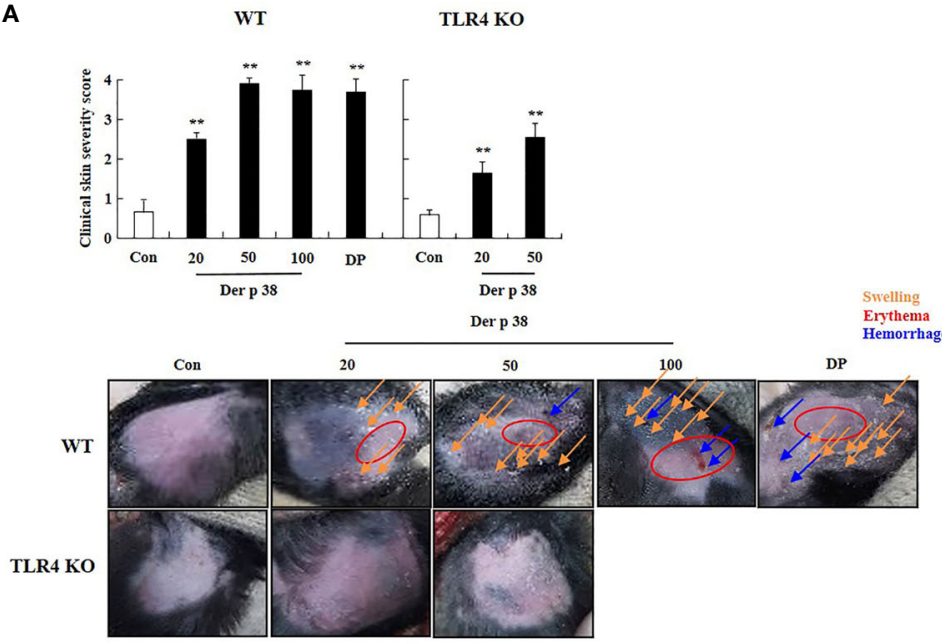

B

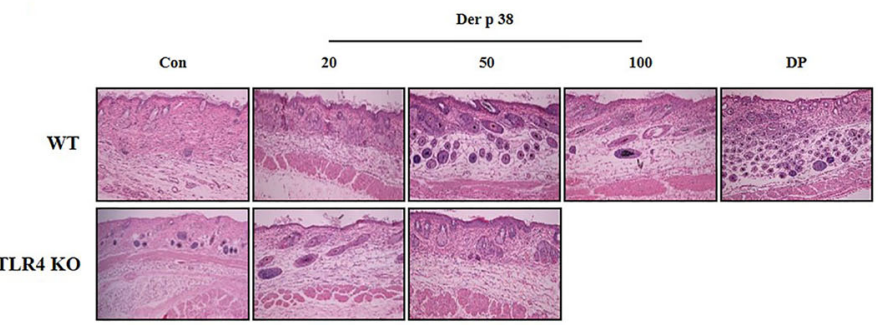

C
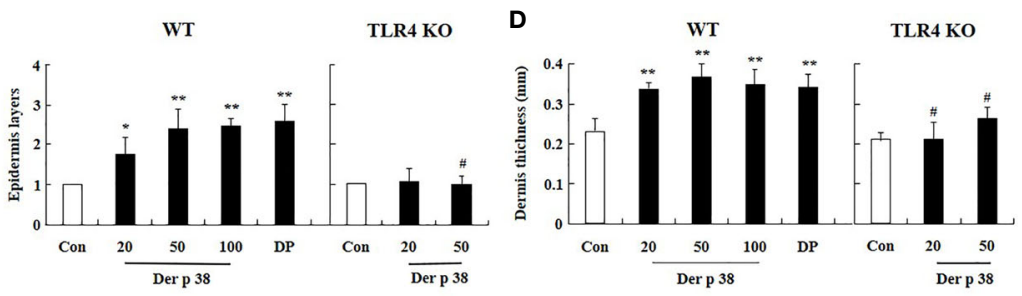

E
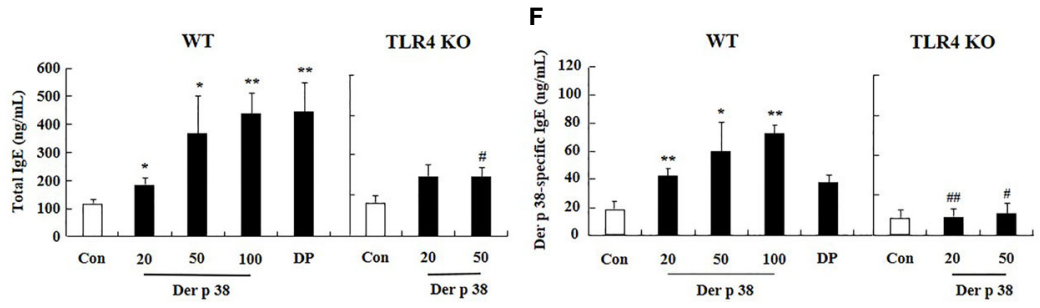

FIGURE 4 | Der p 38 induces AD-like phenotypes via TLR4 in the mice. C57BL/10ScNJ wild type (WT) and C57BL/10ScNJ TLR4 knockout (KO) mice were used in this experiment. The mice were dorsally administered Der p $38(20,50$, or $100 \mu \mathrm{g} / \mathrm{mice})$ or DP (100 $\mu \mathrm{g} / \mathrm{mice})$ using a $2 \times 2 \mathrm{~cm}$ patch of sterile gauze. The mice were wrapped with a band aid. After 6 days, the patch was removed, and $24 \mathrm{~h}$ later a new patch was applied, for a total of five patches over a 5 weeks period. Clinical skin severity score (A), histological features using hematoxylin and eosin stain (B), layers of epidermis (C) and dermis (D), total lgE (E), and Der p 38-specific lgE (F) were evaluated as described in the Materials and Methods section. The data are presented as a mean $\pm S D(n=3) .{ }^{*} p<0.05$ and ${ }^{* *} p<0.01$ indicate a significant difference between the control group and stimulator-treated groups, and ${ }^{\#} p<0.05$ and ${ }^{\# \#} p<0.01$ indicate significant difference between the WT and the TLR4 KO groups.

immunohistological tools and Western blotting. The expressions of loricrin, involucrin and filaggrin were diminished, whereas JNK was activated in the Der p 38 treated groups (Figures 5A-D). As shown in Figures 5E, F, neutrophils and eosinophils were infiltrated into the dermis of skin. The number of mast cells was also increased in the Der p 38-treated group. However, Der p 38 had no effect on the skin barrier proteins and inflammatory cells in the TLR4 KO group. These results clearly indicate that Der p 38 is 
a strong inducer of $\mathrm{AD}$ in vivo, and TLR4 is the main receptor of Der p 38 (Figures 2 and $\mathbf{3}$ ).

\section{DISCUSSION}

Although destruction of filaggrin is an essential step in the induction and aggravation of $\mathrm{AD}$, the specific allergen protein that directly regulates filaggrin expression and its mechanism has yet to be determined. As shown in Figures 2, 3 and 5, Der p 38 sensitization reduces the filaggrin expression in vitro and in vivo. HDM extract induces the downregulation of filaggrin expression. Previous studies reported that the protease allergen assists the entrance of other allergens, and Der $\mathrm{p} 1$ lyses the transmembrane adhesion proteins of tight junctions $(28,29)$. Sar s 3 is directly capable of cleaving filaggrin (30), and lack of filaggrin increases exposure of Fel d 1 and Der p 1 (31). Although it is known that Der p 38 has a direct cleavage activity on filaggrin, Der p 38 may also facilitate the infiltration of other allergens, thereby resulting in the development and aggravation of allergy by protease activity (Figure 1D). Mediators produced by Der p 38 in human keratinocytes inhibit neutrophil apoptosis as well as filaggrin expression (Figures 3A, D). The increased expressions of IL-6, IL-8, and MCP-1 by Der p 38 may assist in suppression of neutrophil apoptosis, as determined in our previous paper (15) (Figure 3B). Additionally, there was increased infiltration of neutrophils in the skin of the mice (Figure 5E). Der p 38 also enhanced the number of eosinophils in the skin. Th2 cytokines such as IL-4, IL-5, and IL-13, and Th2 promoting cytokines such as IL-33, are reported to block filaggrin expression $(3,32)$. These cytokines function as survival factors of eosinophils by inhibiting apoptosis. However, the Der p 38-treated supernatant exerted no effect on eosinophil apoptosis (Figure 3D). Further studies are required to investigate the exact cytokines that downregulate filaggrin expression, and their interaction with eosinophil infiltration.

TLR4 is considered as an important receptor of the Der $\mathrm{p} 38$ inducing $\mathrm{AD}$ pathogenic mechanism, although deletion of TLR4 does not block the Der p 38-induced AD severity completely (Figure 4). In contrast to our results, the upregulation of TLR4 expression may be related to modulation of $\mathrm{AD}$ development as well as protection of infection. Deficiency of TLR4 induces the aggravation of $\mathrm{AD}$ after 2,4-dinitrochlorobenzene (DNCB) administration, via increased Th2 responses (22). In addition, TLR4 suppresses the pathogenic mechanism of $\mathrm{AD}$ induced by
A

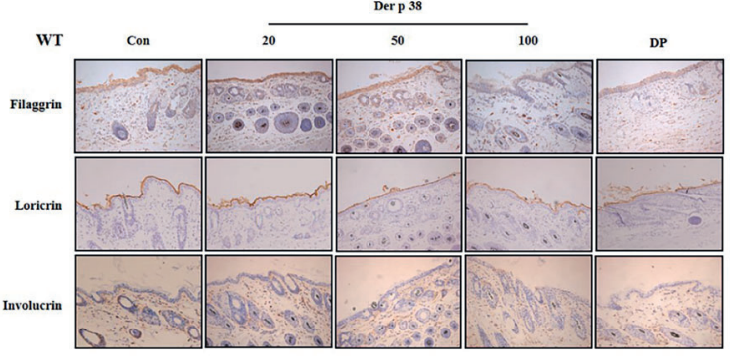

C

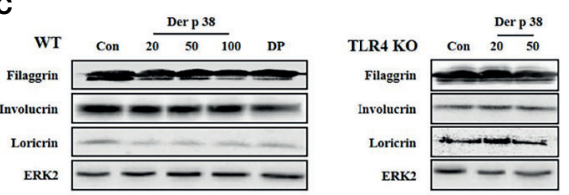

E

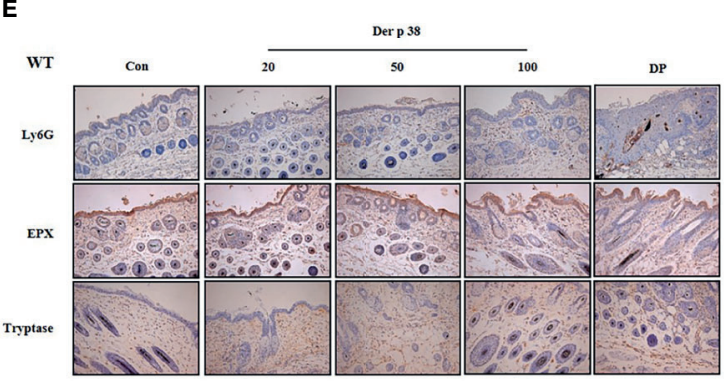

B

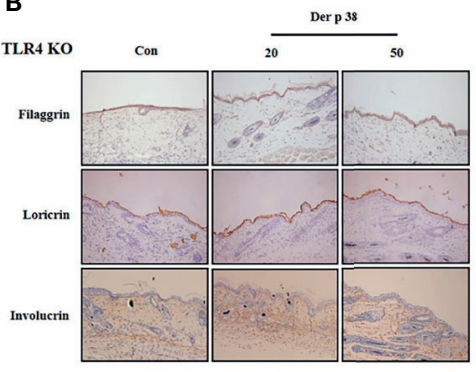

D

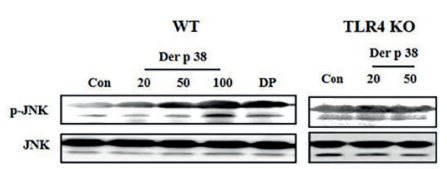

$\mathbf{F}$

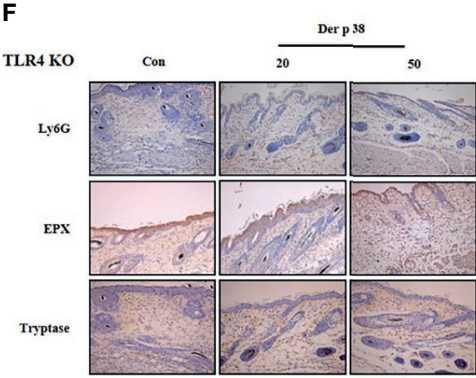

FIGURE 5 | Der $p 38$ decreases the expression of filaggrin and increases neutrophils, eosinophils and mast cells in the skin of mice. (A, B, E, F) For skin barrier proteins and inflammatory cell analysis, skin sections of wild type (WT) (A, E) and TLR4 KO mice (B, F) were fixed, embedded in paraffin, and incubated with primary antibodies against filaggrin, loricrin, involucrin, Ly6G, eosinophil peroxidase (EPX) and tryptase. The samples were examined by light microscopy (magnification, $\times 200)$. Filaggrin, loricrin, involucrin (C), and phospho-JNK (D) in tissue lysates were analyzed by Western blotting. 


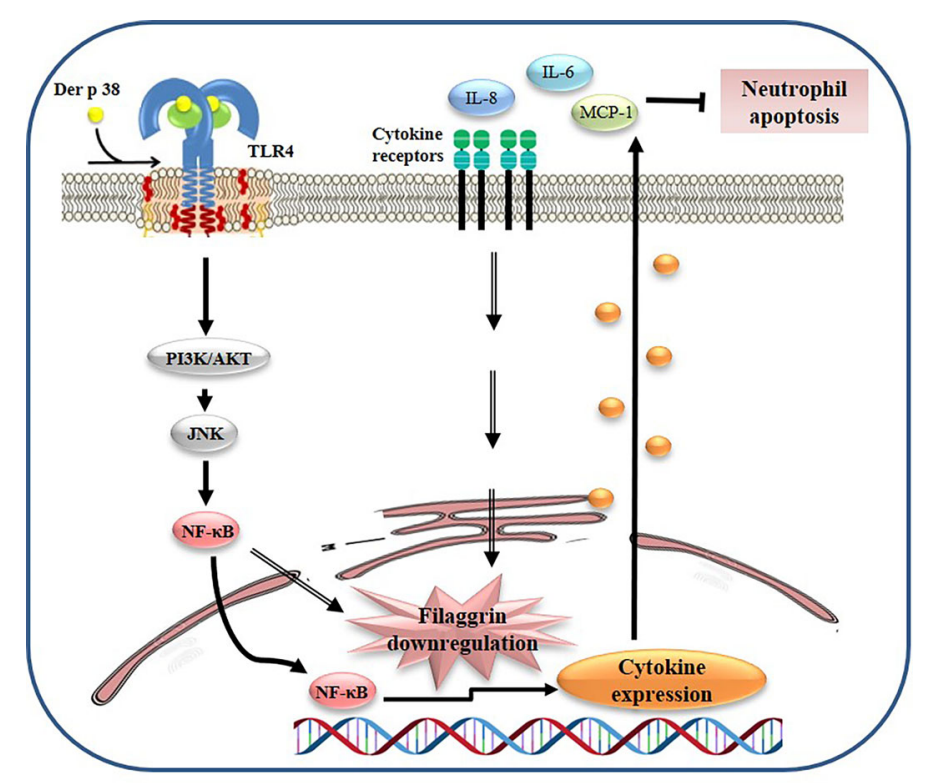

FIGURE 6 | Proposed mechanism of filaggrin downregulation due to Der $p 38$ in AD. Der $p 38$ suppresses filaggrin expression and induces cytokine release through TLR4, PI3K, AKT, JNK, and NF-KB, which blocks neutrophil apoptosis.

Aspergillus fumigatus extracts (20). The data of other research groups are not associated with specific allergen proteins. Der $\mathrm{p} 2$ triggers the clinical features of AD via TLR2 but not TLR4, despite Der $\mathrm{p} 2$ being an MD2-like protein and inducing asthmatic inflammation through TLR4 $(17,23)$. In fact, TLR4 expression prevents the Der $\mathrm{p} 2$-induced allergic reactions, thereby questioning the fact that Der $\mathrm{p} 2$ is a TLR4-binding allergen. We think that for the first time, our results demonstrate that the Der p 38 allergen triggers $\mathrm{AD}$ and probably worsens the disease via TLR4. In addition, LPS suppressed filaggrin expression and induced cytokine secretion like Der p 38 (Supplementary Figure 3) (Figures 2 and 3). This finding contributes to understanding the role of TLR4 in AD pathogenesis, compared to the current concept of TLR4. Der p 38, the TLR4 binding mite allergen, inhibits filaggrin expression via TLR4-related downstream cascade, including PI3K,

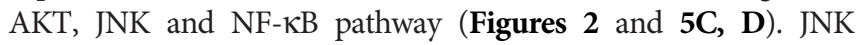
activation is a pivotal signal protein in downregulation of filaggrin expression, but NF-kB is not related to the decreased expression (8). In fact, AKT activation is related to keratinocyte differentiation, and mTORC2 kinase phosphorylates the AKT responsible for filaggrin processing $(33,34)$. Skin barrier disruption exerts upregulation of pro-inflammatory cytokine expressions in relapsing chronic inflammation, and vice versa. Hence, Der p 38 may aggravate $\mathrm{AD}$ symptoms via the common pathways (PI3K, AKT, JNK and $\mathrm{NF}-\kappa \mathrm{B}$ ) involved in filaggrin downregulation and cytokine upregulation. Identification of detailed signal mechanism is required to confirm the more precise role of Der p 38 and elucidate an approach of drug development for $\mathrm{AD}(35,36)$.

Neutrophils are the first protectors against infections. Lack of neutrophils causes $\mathrm{AD}$ subjects to be very sensitive to the infections, and results in $\mathrm{AD}$ exacerbation $(37,38)$. Der $\mathrm{p} 2$ has no effect on neutrophil infiltration, and addition of LPS to Der $\mathrm{p} 2$ treatment enhances the neutrophil movement (23). Allergens such as Der $\mathrm{p} 1$ and Der p 2 enhance the expressions of T cells, eosinophils and mast cells in the skin $(23,39)$. Studies have reported the association of neutrophilic inflammation with $\mathrm{AD}(40,41)$. A recent paper has demonstrated that neutrophils are strongly required for the itch that appears during the development of AD. CXCR3-positive sensory neutrons stimulated with CXCL10 are dependent on the itch induced by neutrophils (42). Neutrophilic inflammation, along with mast cells and eosinophils, have been demonstrated in the skin of Der p 38-adminstered mice (Figures 5E, F), and the mechanism related to the inflammation was confirmed by discovering the anti-apoptotic signal pathway induced by Der $p$ 38 in human neutrophils (Figure 3D). Currently, the role of neutrophils is unknown in $\mathrm{AD}$ pathogenesis induced by Der $\mathrm{p}$ 38 , and this puzzle is targeted to be solved in the near future.

Our findings have identified the novel allergen, Der p 38, which induces $\mathrm{AD}$ pathogenesis by downregulation of filaggrin and upregulation of inflammatory responses such as cytokine secretion and neutrophil survival (Figure 6). The pathogenic mechanism of Der p 38 involves signal proteins such as TLR4, $\mathrm{PI} 3 \mathrm{~K}, \mathrm{AKT}, \mathrm{JNK}$, and NF- $\mathrm{KB}$. It would help us to understand the association of $\mathrm{HDM}$ with $\mathrm{AD}$, for effectively developing preventive or therapeutic strategies to combat this disease.

\section{DATA AVAILABILITY STATEMENT}

The datasets presented in this study can be found in online repositories. The names of the repository/repositories and accession number(s) can be found in the article/Supplementary Material. 


\section{ETHICS STATEMENT}

The human blood protocol and associated consent forms were reviewed and approved by the Institutional Review Board (IRB) of the Eulji University. The patients/participants provided their written informed consent to participate in this study. All experimental animal procedures were performed in accordance with protocols approved by the Institutional Animal Care and User Committee of Eulji University.

\section{AUTHOR CONTRIBUTIONS}

$\mathrm{HJ}$ and GK designed the research and performed most of the experiments. $\mathrm{AK}, \mathrm{MH}, \mathrm{J}-\mathrm{SL}$, and $\mathrm{YH}$ helped conducting the experiments related to animal, and healthy and allergic subjects. BSP analyzed structure of Der p 38. EJY and ISK contributed to the design of the study and supervised the project. All authors contributed to the article and approved the submitted version.

\section{FUNDING}

This research was supported by National Research Foundation of Korea (NRF) grant funded by the Korea government Ministry of Science and ICT (No. 2017R1C1B507674614).

\section{REFERENCES}

1. Weidinger S, Novak N. Atopic Dermatitis. Lancet (2016) 387:1109-22. doi: 10.1016/S0140-6736(15)00149-X

2. Bieber T. Atopic Dermatitis. N Engl J Med (2008) 358:1483-94. doi: 10.1056/ NEJMra074081

3. Sullivan M, Silverberg NB. Current and Emerging Concepts in Atopic Dermatitis Pathogenesis. Clin Dermatol (2017) 35:349-53. doi: 10.1016/ j.clindermatol.2017.03.006

4. Weidinger S, Beck LA, Kabashima K, Irvine AD. Atopic Dermatitis. Nat Rev Dis Primers (2018) 4:1-10. doi: 10.1038/s41572-018-0001-Z

5. Peng W, Novak N. Pathogenesis of Atopic Dermatitis. Clin Exp Allergy (2015) 45:566-74. doi: 10.1111/cea.12495

6. Lee AY. Molecular Mechanism of Epidermal Barrier Dysfunction as Primary Abnormalities. Int J Mol Sci (2020) 21:1194. doi: 10.3390/ ijms21041194

7. Palmer CN, Irvine AD, Terron-Kwiatkowski A, Zhao Y, Liao H, Lee SP, et al. Common Loss-of-Function Variants of the Epidermal Barrier Protein Filaggrin Are a Major Predisposing Factor for Atopic Dermatitis. Nat Genet (2006) 38:441-46. doi: 10.1038/ng1767

8. Kim BE, Howell MD, Guttman-Yassky E, Gilleaudeau PM, Cardinale IR, Boguniewicz $M$, et al. TNF- $\alpha$ Downregulates Filaggrin and Loricrin Through C-Jun N-Terminal Kinase: Role for TNF- $\alpha$ Antagonists to Improve Skin Barrier. J Invest Dermatol (2011) 131:1272-79. doi: 10.1038/ jid.2011.24

9. Cha KJ, Song CS, Lee JS, Kashif A, Hong MH, Kim G, et al. Chaenomeles Sinensis Koehne Extract Suppresses the Development of Atopic DermatitisLike Lesions by Regulating Cytokine and Filaggrin Expression in NC/Nga Mice. Int J Med Sci (2019) 16:1604-13. doi: 10.7150/ijms.37854

10. Tomas WR, Hales BJ, Smith WA. House Dust Mite Allergens in Asthma and Allergy. Trends Mol Med (2010) 16:321-28. doi: 10.1016/j.molmed.2010.04.008

11. Miller JD. The Role of Dust Mites in Allergy. Clin Rev Allergy Immunol (2019) 57:312-29. doi: 10.5415/apallergy.2013.3.2.79

12. Kim KH. Overview of Atopic Dermatitis. Asia Pac Allergy (2013) 3:79-87. doi: 10.5415/apallergy.2013.3.2.79

\section{ACKNOWLEDGMENTS}

We thank all our volunteers to provide their peripheral blood samples for our study.

\section{SUPPLEMENTARY MATERIAL}

The Supplementary Material for this article can be found online at: https://www.frontiersin.org/articles/10.3389/fimmu.2021. 646316/full\#supplementary-material

Supplementary Figure 1 | Der p 38 directly binds to TLR4. Recombinant Der $p$ 38 protein was added to a TLR4-bound column, eluted, and separated by SDSPAGE. The gel was stained with silver stain.

Supplementary Figure 2 | Der p 38 has no effect on total and surface TLR4 expression in $\mathrm{HaCaT}$ cells. (A, B) HaCaT cells were treated with $10 \mu \mathrm{g} / \mathrm{mL}$ Der p 38 in the indicated time. The harvested cells were lysed, and TLR4 expression was detected by Western blotting (A) and flow cytometry (B)

Supplementary Figure 3 | LPS diminishes filaggrin expression and induces cytokine secretion in human keratinocyte HaCaT cells. (A) HaCaT cells were treated with $1 \mu \mathrm{g} / \mathrm{mL}$ LPS for the indicated time or $10 \mu \mathrm{g} / \mathrm{mL}$ Der $\mathrm{p} 38$ for $48 \mathrm{~h}$. The harvested cells were lysed, and filaggrin expression was analyzed by Western blotting. (B) The cells were treated with $1 \mu \mathrm{g} / \mathrm{mL}$ LPS or $10 \mu \mathrm{g} / \mathrm{mL}$ Der p 38 for $48 \mathrm{~h}$. The supernatant was collected and analyzed by ELISA. The data are presented relative to the control (Con), which was set at $100 \%$ as the mean \pm S.D. ${ }^{\star *} p<0.01$ indicates a significant difference between the untreated and LPS or Der $\mathrm{p}$ 38-treated groups,

13. Mueller GA, Glesner J, Daniel JL, Zhang J, Hyduke N, Richardson CM, et al. Mapping Human Monoclonal IgE Epitopes on the Major Dust Mite Allergen Der P 2. J Immunol (2020) 205:1999-07. doi: 10.4049/jimmunol.2000295

14. Hammad H, Chieppa M, Perros F, Willart MA, Germain RN, Lambrecht BN. House Dust Mite Allergen Induces Asthma via Toll-Like Receptor 4 Triggering of Airway Structural Cells. Nat Med (2009) 15:410-16. doi: 10.1038/nm.1946

15. Kim EH, Lee JS, Lee NR, Baek SY, Kim EJ, Lee SJ, et al. Regulation of Constitutive Neutrophil Apoptosis Due to House Dust Mite Allergen in Normal and Allergic Rhinitis Subjects. PloS One (2014) 9:e105814. doi: 10.1371/journal.pone.0105814

16. Koller B, Müller-Wiefel AS, Rupec R, Korting HC, Ruzicka T. Chitin Modulates Innate Immune Responses of Keratinocytes. PloS One (2011) 6: e16594. doi: 10.1371/journal.pone.0016594

17. Trompette A, Divanovic S, Visintin A, Blanchard C, Hegde RS, Madan R, et al. Allergenicity Resulting From Functional Mimicry of a Toll-Like Receptor Complex Protein. Nature (2009) 457:585-88. doi: 10.1038/nature07548

18. Mandron M, Ariès MF, Boralevi F, Martin H, Charveron M, Taieb A, et al. Age-Related Differences in Sensitivity of Peripheral Blood Monocytes to Lipopolysaccharide and Staphylococcus Aureus Toxin B in Atopic Dermatitis. J Invest Dermatol (2008) 128:882-89. doi: 10.1038/sj.jid.5701112

19. Panzer R, Blobel C, Fölster-Holst R, Proksch E. TLR2 and TLR4 Expression in Atopic Dermatitis, Contact Dermatitis and Psoriasis. Exp Dermatol (2014) 23:364-66. doi: 10.1111/exd.12383

20. Brandt EB, Gibson AM, Bass S, Rydyznski C, Khurana Hershey GK. Exacerbation of Allergen-Induced Eczema in TLR4- and TRIF-Deficient Mice. J Immunol (2013) 191:3519-25. doi: 10.4049/jimmunol.1300789

21. Tao Y, Wang Y, Wang X, Wang C, Bao K, Ji L, et al. Calycosin Suppresses Epithelial Derived Initiative Key Factors and Maintains Epithelial Barrier in Allergic Inflammation via TLR4-Mediated NF-אb Pathway. Cell Physiol Biochem (2017) 44:1106-19. doi: 10.1159/000485416

22. Lin L, Xie M, Chen X, Yu Y, Liu Y, Lei K, et al. Toll-Like Receptor 4 Attenuates a Murine Model of Atopic Dermatitis Through Inhibition of Langerin-Positive DCs Migration. Exp Dermatol (2018) 27:1015-22. doi: 10.1111/exd.13698

23. Stremnitzer C, Jensen-Jarolim E. Epicutaneously Applied Der P 2 Induces a Strong $\mathrm{T}_{\mathrm{H}}$ 2-Biased Antibody Response in C57BL/6 Mice, Independent of Functional TLR4. Allergy (2014) 69:741-51. doi: 10.1111/all.12399 
24. Lee JS, Lee NR, Kahif A, Yang SJ, Nam AR, Song IC, et al. S100A8 and S100A9 Promote Apoptosis of Chronic Eosinophilic Leukemia Cells. Front Immunol (2020) 11:1258. doi: 10.3389/fimmu.2020.01258

25. Weghofer M, Grote M, Resch Y, Casset A, Kneidinger M, Kopec J, et al. Identification of Der P 23, A Peritrophin-Like Protein, as a New Major Dermatophagoides Pteronyssinus Allergen Associated With the Peritrophic Matrix of Mite Fecal Pellets. J Immunol (2013) 190:3059-67. doi: 10.4049/ jimmunol.1202288

26. Asturias JA, Arilla MC, Gómez-Bayón N, Martínez A, Martínez J, Palacios R. Sequencing and High Level Expression in Escherichia Coli of the Tropomyosin Allergen (Der P 10) From Dermatophagoides Pteronyssinus. Biochim Biophys Acta (1998) 1397:27-30. doi: 10.1016/s0167-4781(98)00006-2

27. Kim DH, Gu A, Lee JS, Yang EJ, Kashif A, Hong MH, et al. Suppressive Effects of S100A8 and S100A9 on Neutrophil Apoptosis by Cytokine Release of Human Bronchial Epithelial Cells in Asthma. Int J Med Sci (2020) 17:498-09. doi: 10.7150/ijms.37833

28. Zhang J, Chen J, Robinson C. Cellular and Molecular Events in the Airway Epithelium Defining the Interaction Between House Dust Mite Group 1 Allergens and Innate Defences. Int J Mol Sci (2018) 19:3549. doi: 10.3390/ ijms19113549

29. Jacquet A, Robinson C. Proteolytic, Lipidergic and Polysaccharide Molecular Recognition Shape Innate Responses to House Dust Mite Allergens. Allergy (2020) 75:33-53. doi: 10.1111/all.13940

30. Beckham SA, Boyd SE, Reynolds S, Willis C, Johnstone M, Mika A, et al. Characterization of a Serine Protease Homologous to House Dust Mite Group 3 Allergens From the Scabies Mite Sarcoptes Scabiei. J Biol Chem (2009) 284:34413-22. doi: 10.1074/jbc.M109.061911

31. Simpson A, Brough HA, Haider S, Belgrave D, Murray CS, Custovic A. EarlyLife Inhalant Allergen Exposure, Filaggrin Genotype, and the Development of Sensitization From Infancy to Adolescence. J Allergy Clin Immunol (2020) 145:993-01. doi: 10.1016/j.jaci.2019.08.041

32. Imai Y. Interleukin-33 in Atopic Dermatitis. J Dermatol Sci (2019) 96:2-7. doi: 10.1016/j.jdermsci.2019.08.006

33. Naeem AS, Zhu Y, Di WL, Marmiroli S, O’Shaughnessy RF. AKT1-Mediated Lamin a/C Degradation Is Required for Nuclear Degradation and Normal Epidermal Terminal Differentiation. Cell Death Differ (2015) 22:2123-32. doi: $10.1038 /$ cdd.2015.62

34. Ding X, Willenborg S, Bloch W, Wickström SA, Wagle P, Brodesser S, et al. Epidermal Mammalian Target of Rapamycin Complex 2 Controls Lipid Synthesis and Filaggrin Processing in Epidermal Barrier Formation. J Allergy Clin Immunol (2020) 145:283-00. doi: 10.1016/j.jaci.2019.07.033

35. Amano W, Nakajima S, Kunugi H, Numata Y, Kitoh A, Egawa G, et al. The Janus Kinase Inhibitor JTE-052 Improves Skin Barrier Function Through
Suppressing Signal Transducer and Activator of Transcription 3 Signaling. J Allergy Clin Immunol (2015) 136:667-77. doi: 10.1016/j.jaci.2015.03.051

36. Kusari A, Han AM, Schairer D, Eichenfield LF. Atopic Dermatitis: New Developments. Dermatol Clin (2019) 37:11-20. doi: 10.1016/j.det.2018.07.003

37. De Benedetto A, Agnihothri R, McGirt LY, Bankova LG, Beck LA. Atopic Dermatitis: A Disease Caused by Innate Immune Defects? J Invest Dermatol (2009) 129:14-30. doi: 10.1038/jid.2008.259

38. Werfel T. The Role of Leukocytes, Keratinocytes, and Allergen-Specific IgE in the Development of Atopic Dermatitis. J Invest Dermatol (2009) 129:1878-91. doi: 10.1038/jid.2009.71

39. Szalai K, Kopp T, Lukschal A, Stremnitzer C, Wallmann J, Starkl P, et al. Establishing an Allergic Eczema Model Employing Recombinant House Dust Mite Allergens Der P 1 and Der P 2 in BALB/c Mice. Exp Dermatol (2012) 21:842-46. doi: 10.1111/exd.12015

40. Koro O, Furutani K, Hide M, Yamada S, Yamamoto S. Chemical Mediators in Atopic Dermatitis: Involvement of Leukotriene B4 Released by a Type I Allergic Reaction in the Pathogenesis of Atopic Dermatitis. J Allergy Clin Immunol (1999) 103:663-70. doi: 10.1016/s0091-6749(99)70240-x

41. Choy DF, Hsu DK, Seshasayee D, Fung MA, Modrusan Z, Martin F, et al. Comparative Transcriptomic Analyses of Atopic Dermatitis and Psoriasis Reveal Shared Neutrophilic Inflammation. J Allergy Clin Immunol (2012) 130:1335-43. doi: 10.1016/j.jaci.2012.06.044

42. Walsh CM, Hill RZ, Schwendinger-Schreck J, Deguine J, Brock EC, Kucirek N, et al. Neutrophils Promote CXCR3-Dependent Itch in the Development of Atopic Dermatitis. Elife (2019) 8:e48448. doi: 10.7554/eLife.48448

Conflict of Interest: The authors declare that the research was conducted in the absence of any commercial or financial relationships that could be construed as a potential conflict of interest.

Publisher's Note: All claims expressed in this article are solely those of the authors and do not necessarily represent those of their affiliated organizations, or those of the publisher, the editors and the reviewers. Any product that may be evaluated in this article, or claim that may be made by its manufacturer, is not guaranteed or endorsed by the publisher.

Copyright (c) 2021 Jeon, Kim, Kashif, Hong, Lee, Hong, Park, Yang and Kim. This is an open-access article distributed under the terms of the Creative Commons Attribution License (CC BY). The use, distribution or reproduction in other forums is permitted, provided the original author(s) and the copyright owner(s) are credited and that the original publication in this journal is cited, in accordance with accepted academic practice. No use, distribution or reproduction is permitted which does not comply with these terms. 